\title{
UM ESTUDO SOBRE A DEMANDA DO CURSO TÉCNICO DE NÍVEL MÉDIO SUBSEQUENTE EM PESCA DO INSTITUTO FEDERAL DO CEARÁ, CAMPUS ACARAÚ
}

\author{
JULIANE VARGAS \\ Instituto Federal de Educação, Ciência e Tecnologia do Ceará (IFCE), Campus de Paracuru \\ $<$ julianebsbvargas@gmail.com>
}

DOI: $10.21439 /$ conexoes.v14i2.1311

\begin{abstract}
Resumo. O presente trabalho se propôs a estudar a demanda do Curso Técnico de Nível Médio Subsequente em Pesca do Instituto Federal do Ceará, campus Acaraú. Desde a implantação do curso a demanda foi baixa, apesar da vocação histórica do município voltada à atividade da pesca. Nesse sentido, o objetivo geral da pesquisa foi investigar em que medida os alunos do $3^{\circ}$ ano do ensino médio das escolas públicas de Acaraú e seus Distritos, principal público alvo do curso, se interessam por cursos técnicos, em especial pelo curso de pesca. O trabalho teve como objetivo específico discriminar os cursos de preferência dos alunos $3^{\circ}$ ano do Ensino Médio das Escolas Públicas de Acaraú após a conclusão do ensino médio. A perspectiva utilizada foi o estudo de campo. Como suporte teórico traçou-se o panorama legal da pesca e as políticas públicas destinadas a esse segmento. A pesquisa de abordagem mista, quantitativa e qualitativa, utilizou como instrumento de coleta de dados a aplicação de questionário estruturado aos alunos do $3^{\circ}$ ano do ensino médio das escolas públicas de Acaraú e Distritos. Os resultados obtidos apontaram o interesse maior dos concluintes do ensino médio por cursos em nível de graduação. A falta de informação sobre o curso e sua proposta foram outros fatores que levaram à baixa demanda do curso.
\end{abstract}

Palavras-chaves: Pesca. Políticas Públicas. Curso Técnico Subsequente. Oferta. Demanda.

\section{A STUDY ON THE DEMAND FOR THE TECHNICAL COURSE OF SUBSEQUENT MEDIUM LEVEL IN FISHING OF THE FEDERAL INSTITUTE OF CEARÁ, CAMPUS ACARAÚ}

\begin{abstract}
The aim of this study is to examine the demand of the subsequent technical course in fishing at Federal Institute of Ceará (IFCE), Acaraú campus. The low demand has been shown since the course implementation, despite the historical vocation of the city dedicated to the fishing activity. In this sense, the general objective of this research was to investigate the extent to which students of the 3rd year of high school in public schools of Acaraú and its districts, the main target audience of the course, are interested in technical courses, in particular the fishing course. The specific objective of the study was to discriminate the favorite courses of the 3rd year High School students of the Public Schools in Acaraú after the conclusion of high school. The study was conducted as a field study. For theoretical support, it was outlined a legal fishing panorama and the public policies to this segment. The research used a mixed quantitative and qualitative approach, and used a data collection application of structured questionnaires to students of the 3rd year of high school in Public Schools in Acaraú and its Districts. The results showed a greater interest of high school students to graduation courses. The lack of information about the course and its proposal are other factors that lead to low demand of the course. The construction of local production arrangements and the approach of the Institute with the fishing community through outreach activities that raise self-esteem in this category and stimulate entrepreneurship and associations can contribute to the increase in demand.
\end{abstract}

Keywords: Fishing. Public policy. Subsequent Technical Course. Offer. Demand. 


\section{INTRODUÇÃO}

Na última década, o Brasil apresentou elevado índice de crescimento econômico, sobretudo se comparado às economias da Europa e América do Norte. Tal fato, aliado ao controle inflacionário existente desde o governo de Fernando Henrique Cardoso (Plano Real), permitiu uma evolução da área educacional, tanto no setor público quanto no privado.

Neste contexto, foi instituída, por meio da Lei $n^{\circ}$ 11.892, de 29 de dezembro de 2008 (BRASIL, 2008b), a Rede Federal de Educação Profissional, Científica e Tecnológica e a criação dos Institutos Federais de Educação, Ciência e Tecnologia (IFs), instituições de ensino superior, básico e profissional, especializadas na oferta de educação profissional e tecnológica nas diferentes modalidades e níveis de ensino.

Atualmente o IFCE é composto por 32 campi, entre os quais a unidade de Acaraú, município com terras banhadas pelo rio Acaraú e também pelo mar. Por se tratar de uma região de grande potencial hídrico, extensa margem litorânea, clima tropical e abrigar comunidades de pescadores que desenvolvem a atividade pesqueira, o campus opera com o eixo tecnológico da área marítimoportuária, voltada à pesca e aquicultura.

À época da pesquisa, a Instituição ofertava 02 (dois) cursos de graduação (Licenciatura em Física e Ciências Biológicas) e 04 (quatro) cursos técnicos de nível médio subsequentes, destinados àqueles que concluíram o Ensino Médio (Pesca, Aquicultura, Construção Naval, Restaurante e Bar). Dentre os 4 cursos técnicos ofertados, o curso de pesca é o que apresentava menor demanda, posicionando-se como última opção em termos de preferência pelos candidatos concorrentes às vagas da Instituição, em sua maioria concluintes do ensino médio das escolas públicas de Acaraú e Distritos.

Tal situação, deveras preocupante aos gestores da entidade, mereceu ser investigada. Assim, a pesquisa partiu das seguintes indagações: em que medida os jovens em idade escolar no Ensino Médio se interessam pela educação profissional e, principalmente, pelo Curso Técnico de Nível Médio em Pesca do IFCE, campus Acaraú? Considerando o potencial e a vocação laboral da região voltados à atividade pesqueira, o que justificaria a baixa demanda?

Para responder a essas perguntas propôs-se a aplicação de um questionário estruturado, dirigido aos alunos do $3^{\circ}$ ano do ensino médio das escolas públicas de Acaraú e seus distritos, objetivando conhecer se estes se interessam por cursos técnicos, em especial, pelo Curso Técnico de Nível Médio Subsequente em Pesca do IFCE, campus Acaraú e discriminar os cursos de preferência dos citados alunos após a conclusão do ensino médio.

O objetivo geral do trabalho foi investigar em que medida os alunos do $3^{\circ}$ ano do ensino médio das esco- las públicas de Acaraú e seus Distritos, principal público alvo do curso, se interessam por cursos técnicos, em especial pelo curso de pesca, ofertado pelo Instituto Federal de Educação, Ciência e Tecnologia do Ceará, campus Acaraú. O trabalho teve como principal objetivo específico discriminar os cursos de preferência dos alunos de $3^{\circ}$ ano do Ensino Médio das Escolas Públicas de Acaraú após a conclusão do ensino médio.

\section{A PESCA E SUAS POLÍTICAS PÚBLICAS}

A pesca no Brasil, embora uma atividade milenar, é questão recente na área educacional. Os últimos anos apontam aumento da demanda nacional e mundial pela proteína derivada do pescado, o que torna o Brasil um potencial produtor em razão de sua extensa faixa litorânea $(8.000 \mathrm{~km})$ e $12 \%$ de toda a água doce do planeta (8,2 bilhões de $m^{3}$ ) (AQUICULTURA. 2014).

Segundo o art. $2^{\mathrm{o}}$, inc. III da Lei $\mathrm{n}^{\mathrm{o}} 11.959$, de 29 de junho de 2009, entende-se por pesca "toda operação, ação ou ato tendente a extrair, colher, apanhar, apreender ou capturar recursos pesqueiros" (BRASIL, 2008a). O artigo $8^{\circ}$ da Lei $\mathrm{n}^{\circ} 11.959 / 2009$ classifica a pesca em comercial e não comercial. A primeira, divide-se em pesca artesanal e industrial; a segunda, em científica - para fins de pesquisa, amadora - lazer e desporto, e a de subsistência, com fins de consumo doméstico ou escambo sem fins lucrativos.

Segundo MALDONADO (1996), a pesca artesanal é caracterizada pela simplicidade da tecnologia e pelo baixo custo de produção. Os pescadores artesanais, também chamados de autônomos, têm na pesca sua maior fonte de renda e não possuem vínculo empregatício com os donos de embarcações. A produção destina-se ao consumo doméstico e à comercialização, sendo esta última dependente de intermediários em razão de não possuírem condições para conservação e transporte mais distante do pescado.

Entre as várias iniciativas governamentais voltadas ao pescador artesanal, visando a melhoria da qualidade de vida e inclusão social, destacam-se os seguintes programas: Pescando Letras, destinado à alfabetização de pescadores e aquicultores; o Programa Nacional de Acesso ao Ensino Técnico e Emprego (PRONATEC) - Pesca e Aquicultura; Projeto de Apoio a Pequenos Empreendimentos na Pesca Artesanal; Parceria Cozinha Brasil e os Telecentros.

Em relação à pesca industrial, esta compreende a utilização de embarcações de médio e grande porte, o uso de tecnologia sofisticada e depende de infraestrutura portuária para o desembarque do pescado, tendo em vista sua atividade se dar em larga escala. Em geral, os pescadores da pesca industrial possuem vínculo de trabalho com o responsável pela embarcação. Este segmento é exclusivamente comercial, de grande importância social e econômica, pois fornece matéria prima 
para as grandes indústrias de centros de distribuição de alimentos.

Quanto às políticas públicas voltadas ao referido segmento, desde o advento da Lei n ${ }^{0} 11.959 / 2009$, estas são destinadas, sobretudo, à modernização da pesca, ao fortalecimento da indústria e do comércio pesqueiros e ao desenvolvimento sustentável, destacando-se o Programa Nacional de Financiamento da Ampliação e Modernização da Frota Pesqueira Nacional (PROFROTA) e o Plano Safra - linhas de crédito com juros reduzidos.

Araújo (2011) afirma que a Lei $n^{0} 11.959 / 2009$ representou um avanço para o setor da pesca e da aquicultura, não apenas por fixar um marco regulatório, mas também por ampliar o acesso ao crédito, reconhecer como atividade pesqueira artesanal a confecção e reparo de petrechos, pequenas embarcações e processamento de pescado.

Azevedo e Pierri (2013), contudo, não compartilham o mesmo entendimento ao discorrerem sobre a política pesqueira atual no Brasil, onde fazem um retrospecto das políticas públicas. Afirmam que anteriormente ao Governo "Lula" a política pesqueira teve três momentos institucionais, com características distintas: o primeiro período, entre 1964 e 1989, foi marcado pelo "desenvolvimentismo modernizante e ambientalmente irresponsável"; o segundo, de 1989 a 1998, em oposição ao anterior, foi caracterizado por uma política essencialmente conservacionista e o terceiro, entre 1998 a 2003, foi permeado por uma disputa institucional "onde a tentativa de retomar o desenvolvimento setorial resultou travada pelas disposições ambientais". (AZEVEDO; PIERRI, 2013, p.1).

No primeiro período, as autoras destacam a SUDEPE, Superintendência do Desenvolvimento da Pesca, órgão competente pelas políticas do setor na época, como a responsável pela política desenvolvimentista, voltada especialmente à pesca industrial. Sob o enfoque econômico, tal política, segundo as autoras, provocou "o maior crescimento histórico contínuo da pesca extrativa" (AZEVEDO; PIERRI, 2013, p.2), contudo, sob o viés ambiental, gerou uma crise nos recursos pesqueiros em razão da sobrepesca 11

Já no segundo período, salientam que as prerrogativas da SUDEPE foram atribuídas ao IBAMA - Instituto Brasileiro do Meio Ambiente e dos Recursos Naturais Renováveis, cuja atuação foi marcada pelo combate à pesca predatória e a adoção de instrumentos de gestão pesqueira destinados à preservação das espécies.

Em 1998, início do terceiro período, foi criado do o DPA (Departamento de Pesca e Aquicultura) junto ao Ministério da Agricultura, com o intuito de retirar a tutela ambiental do setor e recuperar a política desenvolvi-

\footnotetext{
${ }^{1}$ Sobrepesca: Segundo MALDONADO (1996), se refere ao exercício descuidado e predatório da pesca, que causa ameaça às espécies marítimas ou extinção das mesmas.
}

mentista, o que ocasionou significativos conflitos institucionais entre o referido Ministério e o IBAMA em razão da divisão de competências na gestão e ordenamento dos recursos pesqueiros.

Azevedo e Pierri (2013) concluem que, ao longo desses três períodos, a pesca artesanal esteve à margem das preocupações governamentais, vez que as políticas ora se concentravam no desenvolvimento industrial do setor, ora na conservação e proteção dos recursos, fato que prejudicou sobremaneira os pescadores artesanais, os quais, em razão da crise pesqueira, foram condenados ao empobrecimento e à concorrência desleal com a pesca industrial e a aquicultura empresarial.

\section{MATERIAIS E MÉTODOS}

O delineamento metodológico escolhido para a pesquisa foi de uma abordagem mista: quantitativa e qualitativa. A abordagem quantitativa se deu em razão da utilização de recursos estatísticos e dos resultados decorrentes da coleta de dados apresentados por meio de gráficos. Já a abordagem qualitativa, indicada ao tipo de estudo sobre opiniões, valores ou crenças de determinado grupo, mostrou-se hábil para compreender a realidade de forma mais completa.

A pesquisa foi realizada nas escolas públicas de ensino médio do município de Acaraú e seus Distritos. A população pesquisada compreendeu estudantes do $3^{\circ}$ ano do Ensino Médio das Escolas Públicas de Acaraú. O objetivo foi identificar se os concluintes dessa etapa se interessam por cursos técnicos, em especial, pelo Curso Técnico em Pesca.

O Município de Acaraú possui 05 (cinco) escolas públicas estaduais de Ensino Médio: Liceu de Acaraú Maria Alice Ramos Gomes (sede de Acaraú), Tomaz Pompeu de Sousa Brasil (sede de Acaraú), Vicente de Paulo da Costa (distrito de Juritianha), Maria Conceição de Araújo (distrito de Aranaú) e Marta Maria Giffoni de Sousa (sede de Acaraú). Esta última, por ofertar educação profissional, não integrou a pesquisa.

Com a finalidade de delimitar a amostra dos alunos, obteve-se junto à CREDE 3, Coordenadoria Regional de Desenvolvimento da Educação, subordinada à Secretaria de Educação do estado do Ceará, a discriminação das escolas, seus respectivos períodos e a estimativa de alunos ingressantes no $3^{\circ}$ ano do Ensino Médio de 2015

Considerando que o total de alunos estimado para cursar o $3^{\circ}$ ano do ensino médio em 2015 representou um universo muito amplo - 790 - optou-se por trabalhar com uma turma por turno, em cada uma das quatro escolas pesquisadas.

\footnotetext{
${ }^{2}$ Dados fornecidos por $e$-mail, em 04 de dezembro de 2014, pela CREDE 3. O número de alunos na referida relação foi estimado, pois o prazo para encerramento de novas matrículas e transferência dar-se-ia apenas ao final de fevereiro de 2015.
} 
O instrumento eleito foi o questionário estruturado, o qual contemplou questões fechadas, complementadas por abertas, com o intuito de revelar informações não previstas inicialmente e que eventualmente pudessem aprofundar o objeto de estudo, enriquecendo, assim, a investigação. Para tanto, o instrumento reuniu questões ligadas aos cursos de preferência dos participantes e, também, questões relacionadas à divulgação do curso de pesca pelo IFCE.

A coleta de dados nas escolas se deu no período de 14 de maio a 18 de junho de 2015 , nos turnos matutino, vespertino e noturno ( 1 turma por turno), durante o horário de aulas. A amostra não foi aleatória, mas sim por conveniência. As turmas foram escolhidas pelo diretor de cada escola, seguindo a recomendação da pesquisadora para que a escolha recaísse, se possível, na turma mais numerosa. A entrada em sala foi previamente acertada com o professor da turma, que auxiliou a pesquisadora na distribuição e recolhimento dos questionários. No total, foram aplicados 253 questionários nas 4 escolas pesquisadas.

\section{RESULTADOS E DISCUSSÃO}

A análise quantitativa foi realizada por meio de gráficos, ordenados conforme a numeração das questões do questionário estruturado, aplicado aos alunos do terceiro ano do ensino médio. Com esse instrumento buscou-se averiguar se os alunos se interessam pelos cursos técnicos, em especial pelo curso de pesca, ou se preferem, os cursos em nível de graduação. O questionário contemplou, ainda, por meio de questões fechadas, a possibilidade de se averiguar a eficácia da divulgação do curso junto às escolas nas quais o questionário foi aplicado.

O indivíduo que concluir o ensino médio e optar pela continuidade dos estudos poderá ingressar tanto na educação profissional e tecnológica quanto na educação superior, conforme dispõe os artigos 39 e 44 da Lei $n^{\circ}$ 9.394/96 - LDB (BRASIL, 1996).

Os alunos foram indagados (Gráfico 1) se, após o ensino médio, continuariam os seus estudos. O gráfico a seguir indica que 78,3\% deles responderam "sim"; 19,8\% "não sabem"; 1,6\% afirmaram que "não" e apenas $0,4 \%$, que refere-se a um aluno, "não respondeu" a questão.

Os dados indicam que a maioria dos participantes $(78,3 \%)$ considera importante para suas vidas a formação por meio da escola. Observa-se, também, um número expressivo de alunos indecisos (19,8\%), provavelmente por entenderem o ingresso imediato no mercado de trabalho mais vantajoso que o aumento da trajetória formativa.

Outro aspecto investigado foi o curso desejado pelos alunos 2(Gráfico 2), independentemente das oportunidades educacionais existentes. Como trata-se de questão
" Sim = Não = Não sei = Não respondeu

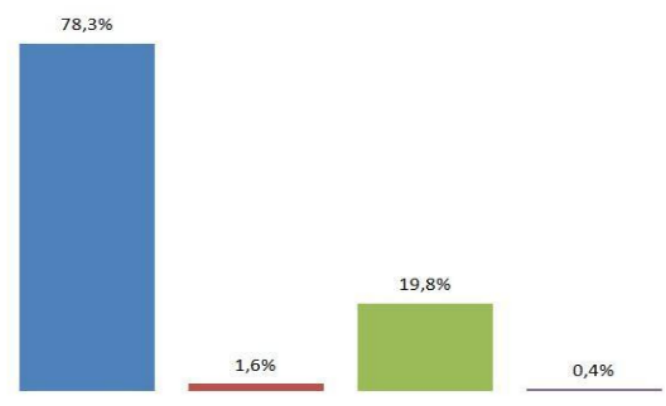

Gráfico 1: Continuação dos estudos após o ensino médio.

Fonte: Elaborado pelos autores (2015).

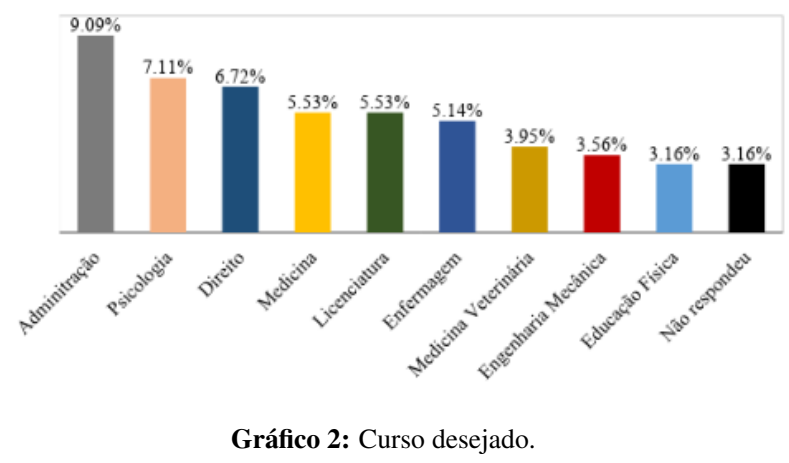

Fonte: Elaborado pelos autores (2015).

aberta e foram analisados 253 questionários - o que representa um universo bem expressivo -, o gráfico abaixo destaca apenas os percentuais referentes aos 10 cursos mais citados pelos entrevistados, além do percentual dos que não responderam a questão.

Os dados apontam uma possível preferência dos estudantes por cursos de graduação e historicamente de maior tradição, como se observa pelos quatro primeiros lugares, na seguinte ordem de preferência: Administração $(9,09 \%)$, Psicologia $(7,11 \%)$, Direito $(6,72 \%)$ e Medicina $(5,53 \%)$.

Pode-se inferir, também, que a preferência dos estudantes pela graduação se justifique em razão do estigma que os cursos técnicos profissionalizantes tiveram durante o percurso histórico da educação brasileira, posto que eram vistos como um ensino destinado às classes economicamente mais pobres. Os cursos superiores, por outro lado, sempre tiveram maior prestígio, uma vez que abarcavam a elite, classe mais privilegiada da sociedade. O gráfico demonstra, também, manifesto desinteresse dos participantes pelos cursos técnicos.

Como desdobramento do gráfico 2, os cursos eleitos foram separados por sexo (Gráficos 3 e 4 ). 


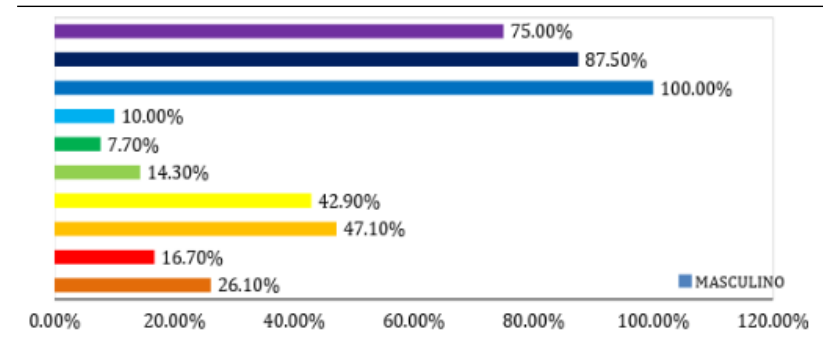

Gráfico 3: Cursos desejados pelos homens.

Fonte: Elaborado pelos autores (2015).

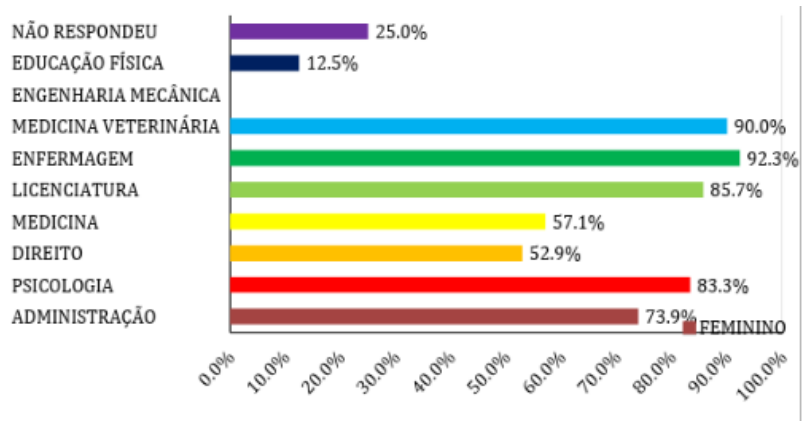

Gráfico 4: Cursos desejados pelas mulheres.

Fonte: Elaborado pelos autores (2015).

Neste gráfico, o percentual dos que não responderam revela um dado interessante: os homens se mostraram mais indecisos do que as mulheres em relação ao seu futuro profissional, excetuando-se, por óbvio, aqueles que não tenham respondido a questão porque optaram pela não continuidade dos estudos após o ensino médio. Outro aspecto a ser relevado é que nenhuma mulher optou por cursar Engenharia Mecânica, curso tradicionalmente ligado ao gênero masculino. Observa-se, também, que um percentual maior de mulheres em relação aos homens optaram por cursos nos quais geralmente estão presentes relações de afeto e troca, como Enfermagem, Licenciatura, Psicologia e Medicina.

Aos alunos foram apresentadas 4 alternativas de cursos (Gráfico 5): Bacharelado, Licenciatura, Tecnologia e Técnico Subsequente (nível médio). Indagou-se aos mesmos qual seria a opção desejada. O gráfico abaixo demonstra que $68 \%$ dos participantes optaram pelo Bacharelado; $11 \%$ pela Licenciatura; $11 \%$ pelo Técnico Subsequente (nível médio); $8 \%$ pelo Tecnológico (técnico de nível superior); $2 \%$ não responderam.

Novamente nota-se a preferência dos participantes pelo bacharelado, pois apenas $11 \%$ dos participantes optou pelos cursos técnicos de nível médio. Uma hipótese passível de explicar essa inclinação pelos cursos de nível superior é o desejo de ascensão social dos participantes

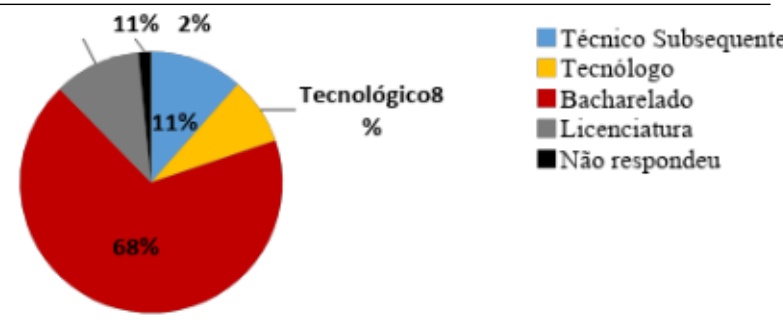

Gráfico 5: Alternativas após a conclusão do ensino médio: bacharelado, licenciatura, técnico e tecnólogo.

Fonte: Elaborado pelos autores (2015).
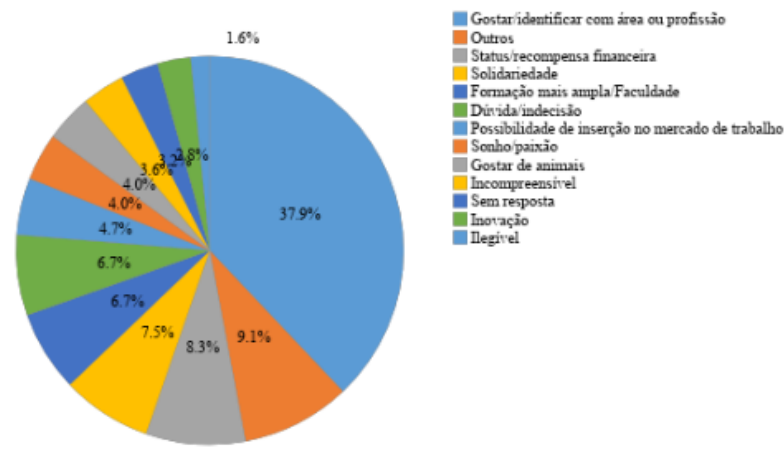

Gráfico 6: Justificativa do gráfico 5

Fonte: Elaborado pelos autores (2015).

e a importância que atribuem a profissões de nível superior. Além disso, é possível que considerem desvantajoso investir o próprio tempo, no mínimo dois anos, em outro curso de nível igual ao que já obtiveram com a conclusão do nível médio.

Como desdobramento do Gráfico 5, solicitou-se aos participantes que justificassem a alternativa escolhida (Gráfico 6): bacharelado, licenciatura, técnico subsequente (nível médio) e tecnólogo (técnico de nível superior). As respostas mais recorrentes, agrupadas em categorias, foram: gostar/identificar com a área ou profissão $(37,9 \%)$; status ou recompensa financeira $(8,3 \%)$; solidariedade $(7,5 \%)$; formação mais ampla/faculdade (6,7\%); dúvida/indecisão (6,7\%); possibilidade de inserção no mercado de trabalho $(4,7 \%)$; sonho ou paixão $(4,0 \%)$; gostar de animais $(4,0 \%)$ e inovação $(2,8 \%)$. Houve, também, respostas incompreensíveis $(3,6 \%)$, questão sem resposta $(3,2 \%)$ e respostas ilegíveis $(1,6 \%)$. As respostas variadas foram categorizadas como "Outras" $(9,1 \%)$.

Os participantes foram indagados se conhecem o IFCE - Instituto Federal de Educação, Ciência e Tecnologia do Ceará (Gráfico 77: 72\% deles assinalaram "sim"; 25\% "não" e 3\% não responderam. O percentual dos que afirmaram "sim" é significativo e indica que o 


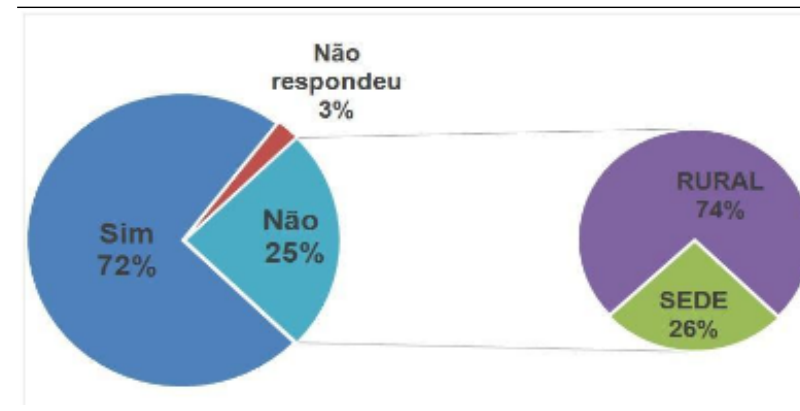

Gráfico 7: Conhece o IFCE?

Fonte: Elaborado pelos autores (2015).

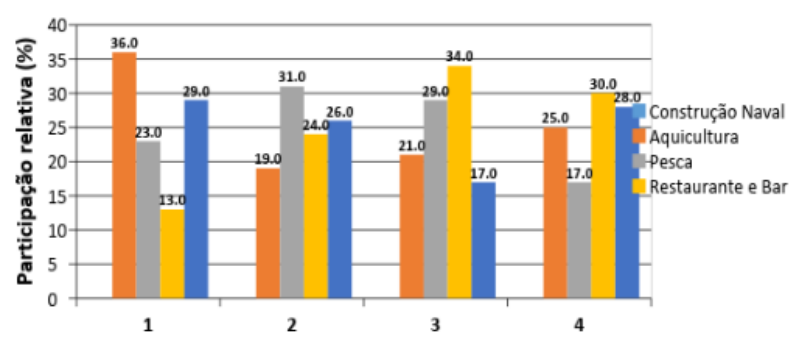

Gráfico 8: Escolhas dos cursos por ordem de preferência.

Fonte: Elaborado pelos autores (2015).

campus é bem conhecido na região. Sua localização é estratégica, fica ao lado do fórum e a menos de um quilômetro das escolas Liceu de Acaraú Maria Alice Ramos Gomes e Tomaz Pompeu de Souza Brasil, fato que facilita a ida, para fins de visitação, dos estudantes dessas escolas ao IFCE/Campus Acaraú.

Um dado que despertou atenção, e merece registro, é em relação ao percentual dos que afirmaram não conhecer o Instituto $-25 \%$. Desses $25 \%$ a maioria dos alunos que desconhece o IFCE, 74\%, é da área rural (Distritos de Aranaú e Juritianha). Isso revela que uma possível deficiência no intercâmbio entre o Instituto e as escolas Maria da Conceição Araújo (Aranaú) e Vicente de Paulo da Costa (Juritianha), provavelmente em razão da distância entre essas localidades e o IFCE/Acaraú.

No gráfico abaixo (Gráfico5) observa-se que o Curso de Pesca lidera a $3^{\mathrm{a}}$ e a $4^{\mathrm{a}}$ opção na preferência dos alunos. Verificou-se, também, que ele figura em último lugar como a primeira opção dos alunos (13\%), demonstrando alta rejeição em relação aos demais cursos.

Na questão 6, os alunos foram perguntados se conhecem o curso de pesca (Gráfico 9): 2,8\% dos pesquisados não responderam a questão; $13,4 \%$ nunca ouviram falar; 64,4\% disseram que não o conhecem, mas já ouviram falar; $19 \%$ afirmaram que o conhecem razoavelmente e $0,4 \%$ afirmou conhecer o curso com profundidade.

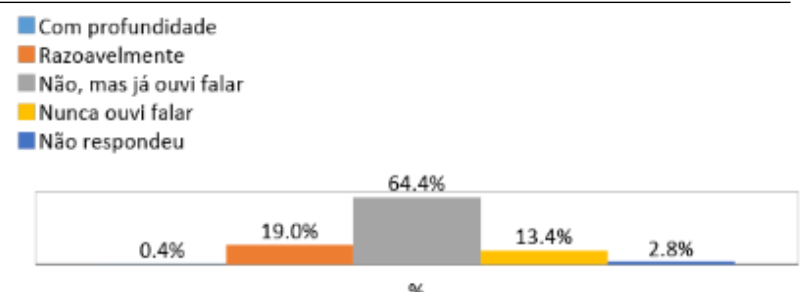

$\%$

Gráfico 9: Você conhece o Curso Técnico em Pesca do IFCE?

Fonte: Elaborado pelos autores (2015).

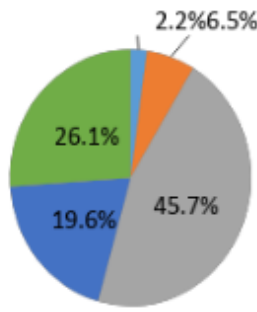

\author{
Rádio \\ Internet \\ Amigos ou parentes que \\ estudam no IFCE \\ Cartazes pela cidade \\ Visita de sua escola ao campus \\ Visita do IFCE na sua escola
}

Gráfico 10: meio de divulgação mais eficaz.

Fonte: Elaborado pelos autores (2015).

Os dados indicam elevado número de alunos que não conhecem o curso $(13,4 \%$ e $64,4 \%$ ), o que sugere uma divulgação precária, especificamente em relação ao curso de pesca, e a necessidade de maior mobilização do Instituto nesse sentido.

Aos alunos que assinalaram "sim" na questão anterior (conhecem o curso de pesca), foi solicitado que apontassem por qual meio de comunicação chegaram a conhecê-lo (Gráfico 10).

Contrariando expectativas da pesquisadora, o rádio, considerado um meio de comunicação bastante eficaz nas cidades do interior do estado, representou apenas $2,2 \%$ das escolhas. Igualmente a internet, meio de comunicação de larga escala, foi o meio eleito por apenas 6,5\% dos participantes. Quanto aos cartazes espalhados pela cidade não foi a escolha de nenhum dos participantes $(0,0 \%)$. O meio de comunicação mais eficaz foi o "boca a boca" de amigos ou parentes que estudam no Instituto (45,7\%), seguido de visita do IFCE nas escolas $(26,1 \%)$ e visita das escolas no campus $(19,6 \%)$.

\section{CONSIDERAÇÕES FINAIS}

Os dados que emergiram da análise quantitativa indicaram a preferência dos alunos por cursos de graduação ao invés dos cursos técnicos, pois a maioria optou pelo bacharelado, em cursos historicamente considerados de maior tradição. Na análise qualitativa, percebeu-se uma maior inclinação dos alunos por cursos com os quais os mesmos mais se identificam. 
Os dados revelaram, ainda, alta rejeição ao curso de pesca e possível deficiência na divulgação do mesmo junto às escolas de ensino médio, sobretudo as localizadas na área rural (Aranaú e Juritianha). Quanto à divulgação do curso, o meio que se mostrou mais eficaz entre os alunos foi o "boca-a-boca", materializado através de amigos ou parentes que estudam no Instituto.

Apesar de variados os fatores que ensejam o desinteresse pelo curso de pesca, ações locais e pontuais talvez possam contribuir com a elevação da demanda. $\mathrm{O}$ aumento da frequência de visitas às escolas e a prévia definição de estratégias de divulgação em conjunto com os alunos do IFCE, maiores responsáveis pela visibilidade do curso, podem ser caminhos viáveis.

\section{REFERÊNCIAS}

AQUICULTURA., M. D. P. E. PESCA. Lei n ${ }^{\circ} 11.892$, de 29 de dezembro de 2008, 2014. Disponível em: $<$ http://www.mpa.gov.br/index.php/pescal >

ARAúJO, S. C. d. Dissertação (Mestrado em Desenvolvimento Sustentáve, Pescando Letras: diálogos interdisciplinares entre a educação ambiental e a alfabetização de jovens e adultos no contexto da pesca artesanal. 2011.

AZEVEDO, N. T.; PIERRI, N. A política pesqueira atual no brasil: a escolha pelo crescimento produtivo em detrimento da pesca artesanal. Samudra Report, v. 64, p. 34-41, 2013.

BRASIL. Estabelece as diretrizes e bases da educação nacional. LEI No 9.394, DE 20 DE DEZEMBRO DE 1996, 1996. Disponível em: <http://goo.gl/QvaB1M>

Dispõe sobre a Política Nacional de Desenvolvimento Sustentável da Aquicultura e da Pesca, regula as atividades pesqueiras, revoga a Lei no 7.679, de 23 de novembro de 1988, e dispositivos do Decreto-Lei $\mathbf{n}^{0} 221$, de 28 de fevereiro de 1967, e dá outras providências. Lei $\mathrm{n}^{\circ} 11.959$, de 29 de junho de 2009, 2008. Disponível em: <http://www.planalto.gov.br/ccivil_03/_ato2007-2010/ 2009/Lei/L11959.html>

Institui a Rede Federal de Educação Profissional, Científica e Tecnológica, cria os Institutos Federais de Educação, Ciência e Tecnologia, e dá outras providências. Lei $n^{0} 11.892$, de 29 de dezembro de 2008, 2008. Disponível em: $<$ http://goo.gl/BbAJAl>

MALDONADO, S. C. Pescadores do mar. São Paulo: Ática, 1996. 